Trabajos y Comunicaciones, 2da. Época, N 46, e042, octubre 2017. ISSN 2346-8971

Universidad Nacional de La Plata.

Facultad de Humanidades y Ciencias de la Educación.

Departamento de Historia

\title{
Presentación al dossier: "A treinta años de Lo nacional-popular en Bolivia de René Zavaleta Mercado"
}

\author{
Jaime Ortega Reyna * y Marcelo Starcenbaum ** \\ * Universidad Autónoma Metropolitana-Xochimilco, México, ** Facultad de Humanidades y \\ Ciencias de la Educaión-Universidad Nacional de La Plata, Argentina | \\ jaime_ortega83@hotmail.com, mstarcenbaum@gmail.com
}

Una anécdota poco conocida da cuenta de la importancia de René Zavaleta Mercado para el encuentro entre la dirigencia del entonces Frente Sandinista de Liberación Nacional (FSLN) y altos cargos del gobierno panameño presidido por el General Torrijos. Aquel encuentro propiciado por el sociólogo boliviano sería crucial para el destino de la revolución nicaragüense de 1979, que encontraría en el gobierno de aquel país un aliado clave para derribar a la dictadura de Somoza. Así como en esta anécdota, podemos encontrar numerosas intervenciones en las que el autor boliviano constituye una figura central. En este caso queremos referirnos a una de ella que tiene su lugar en las coordenadas teóricas. Se trata del proceso de renovación del discurso marxista que aventuró hacia finales de los años setenta y principios de los ochenta y que tendrá en Lo nacional-popular en Bolivia su punto más álgido.

La redacción de Lo nacional-popular en Bolivia tiene lugar en un momento de madurez intelectual plena. Nacido en Oruro el 3 junio de 1937, Zavaleta Mercado ejerce el periodismo desde 1954, es decir dos años después de la "Revolución Nacional”. En esta área de su actividad es de destacar su nombramiento como subdirector del periódico La Nación en 1958, al tiempo que participa de distintas publicaciones (unos años más tarde publicará en Marcha editada en Montevideo y El Día en la Ciudad de México) y es acreedor de lugares destacados en concursos de poesía. En ese mismo año es nombrado - solo por unos meses - agregado cultural de Bolivia en Uruguay. En 1964 actúa como Ministro de Minas y Petróleo, al tiempo que vuelve a la Universidad Mayor de San Andrés a estudiar Derecho, carrera que concluirá en 1969. En éste año se establece en Oxford después de algunos inconvenientes políticos en Bolivia y de algunos períodos de exilio en Uruguay. Además de recibir invitación de la Universidad de Oxford, también es convocado por la Universidad de Vincennes en Francia. En 1971 vuelve a Bolivia en donde funda junto a otros intelectuales el Movimiento de Izquierda Revolucionaria; en ese mismo año tiene que salir al exilio en Chile tras el golpe de Estado comandado por Hugo Banzer. En Chile se establece en el Centro de Estudios de la Realidad Nacional en donde redacta El poder dual. Esta obra, finalmente publicada en México, país al que llega tras salir del exilio en septiembre de 1973, le vale el reconocimiento del científico social consolidado que ya es. En México se integra a la Universidad Nacional Autónoma de México, donde trabaja en lugares claves para el desarrollo de la reflexión social crítica, como lo son el Centro de Estudios 
Latinoamericanos, el Posgrado de Economía y el Instituto de Investigaciones Sociales. Finalmente en 1976 funda junto a otros intelectuales la Facultad Latinoamericana de Ciencias Sociales (FLACSO). En 1980 obtiene una plaza de Profesor-Investigador en el Departamento de Relaciones Sociales de la Universidad Autónoma Metropolitana, en donde colaboró en la fundación del Doctorado en Ciencias Sociales. Amén de esta labor intelectual que comprendió el trabajo periodístico y académico, Zavaleta fue un intelectual cercano a las luchas del pueblo boliviano; además del MIR, se adhirió al Partido Comunista Boliviano. En 1984 cuando el proceso de democratización y de inicio del neoliberalismo en Bolivia es un hecho, comienza la redacción de Lo nacionalpopular en Bolivia, cuya publicación póstuma en 1986 deja un legado inconmensurable para el pensamiento crítico de la región.

El trabajo teórico realizado en este libro tenía varios afluentes. Por un lado, una importancia considerable del Marx de los Grundrisse y El Capital, algo novedoso si se tiene en cuenta la casi absoluta colonización del humanismo y el antropologismo de las interpretaciones del teórico alemán a partir de los Manuscritos de 1844. Los textos de madurez le permitirán a Zavaleta abordar uno de sus temas predilectos: la conformación histórica de la masa proletaria, tan importante para los destinos de Bolivia. Junto a esa lectura de Marx viene también un interés renovado en la figura de Antonio Gramsci, el "Weber de los subalternos". Con el teórico italiano, Zavaleta arriba a una comprensión integral del Estado y de la sociedad, así como el papel de las relaciones de fuerza que cristalizan en aparatos e instituciones diversas. Ambas coordenadas son fundamentales para entender el marco de producción de Lo nacional-popular en Bolivia. Al respecto, no es casual que la primera frase del libro remita al encuentro entre la tradición marxista y la tradición weberiana. Era indudable que el marxismo era el punto de arranque de la crítica, pero que era insuficiente para abordar algunas dinámicas específicas de la realidad latinoamericana. Los fenómenos nacional-populares demandaban la construcción de otras herramientas de análisis. Zavaleta las fue construyendo a lo largo de un amplio diálogo con autores significativos de su época, así como con otros provenientes de cierta acumulación teórica. Además de los autores clásicos, es perceptible la presencia de figuras como Paul Baran, Giacomo Marramao o la crítica a las teorías de la dependencia. En aquel entramado se configuró una forma original, dinámica y productiva de concebir la presencia fundamental de las clases populares en la cristalización de las relaciones de poder.

Podemos decir que Lo nacional-popular en Bolivia es un intento renovado no sólo de problematizar la historia local, sino de apostar a la construcción de claves de lectura e hipótesis de trabajo en donde la historia no sea el reservorio de un telos que se desenvuelve de manera necesaria, sino la constitución conflictiva de sentidos que laten con potencia en la sociedad. Tomarle el pulso a dichas dinámicas es quizá el leitmotiv de la obra. Aunque inconclusa, arroja luces sobre las zonas aún oscuras, aquellas en las que el "clasismo" sin mediaciones nunca pudo iluminar. Pero que también devela estructuras históricas que persisten a pesar de la dinamización totalizante del capital. Son estas particularidades de su aporte lo que convirtieron al boliviano en una referencia central de las discusiones sobre los problemas políticos y teóricos de América Latina. La obra de Zavaleta Mercado representa en la actualidad una cantera productiva de dimensiones conceptuales y esquemas interpretativos para dar cuenta de problemas tales como las formas contemporáneas del capitalismo, la conformación y desarrollo de las clases sociales y el despliegue de las relaciones entre fuerzas sociales y estatalidad.

El presente dossier presenta textos producidos por investigadores especializados en la obra de Zavaleta Mercado y autores que tienen como objeto de reflexión diferentes problemas teóricos y políticos de América Latina. El artículo de Luciana Cadahia constituye un esfuerzo por pensar Lo nacional-popular en Bolivia en clave filosófica, lo cual habilita una caracterización de Zavaleta Mercado como autor de una original ontología de lo social y una aproximación entre el concepto de lo nacional-popular y la dialéctica hegeliana del amo y el esclavo. Por su parte, Robert Cavooris analiza las relaciones cambiantes entre la forma nación y la lucha de clases a lo largo de la obra del boliviano en los marcos de su aproximación a las tendencias de composición y descomposición en el capitalismo contemporáneo. En el aporte de Diego Giller pueden encontrarse un conjunto de claves interpretativas para leer Lo nacional-popular en Bolivia a partir de sus particularidades como texto perteneciente a otra época y como libro póstumo e incompleto. Por otra parte, Jaime Ortega analiza la obra de Zavaleta Mercado en tanto 
desarrollo de una epistemología política en la que se destacan los problemas relativos a la producción del conocimiento y a la teorización de la política. Finalmente, el artículo de Marcelo Starcenbaum explora los lugares de lo nacional-popular en la obra del boliviano a los fines de constatar la presencia de una concepción sobre las relaciones entre política e historia y la fidelidad al acontecimiento revolucionario de 1952. 